\title{
OPEM
}

www.opem.org

Oriental Pharmacy and Experimental Medicine 2009 9(4), 277-284

DOI 10.3742/OPEM.2009.9.4.277

\section{In vitro anti-oxidant activity of the leaves of Dillenia indica}

\author{
Moni Rani Saha ${ }^{1}$, Md Ashraful Alam ${ }^{1, *}$, SM Raquibul Hasan ${ }^{1}$, Raushanara Akter ${ }^{1}$, Md Mokarram \\ Hossain ${ }^{1}$, Ehsanul Hoque Mazumder ${ }^{2}$ and Md Sohel Rana ${ }^{2}$ \\ ${ }^{1}$ Department of Pharmacy, Stamford University, Bangladesh; ${ }^{2}$ Jahangirnagar University, Saver, Dhaka, Laboratory of \\ Pharmacognosy and Pharmacology, Department of Pharmacy, Stamford University, Bangladesh
}

Received for publication April 22, 2008; accepted April 29, 2009

\begin{abstract}
SUMMARY
The methanol extract of Dillenia indica was tested for antioxidant activity as determined by free radical scavenging of DPPH radical scavenging assay, reducing power, total antioxidant capacity measured by phosphomolybdenum method, total phenolic content and total flavonoids content determination assays. The extract showed significant activities in all antioxidant assays compared to the standard antioxidant in a dose dependent manner. In DPPH radical scavenging assay the $\mathrm{IC}_{50}$ value of the extract was found to be $100.53 \mu \mathrm{g} / \mathrm{ml}$ while ascorbic acid has the $\mathrm{IC}_{50}$ value $58.92 \mu \mathrm{g} / \mathrm{ml}$. Dillenia indica extract showed strong reducing power and total antioxidant capacity. Moreover, methanol extracts also possess high amount of phenolics and flavovonoids and expressed as gallic acid and rutin equivalent respectively. The remarkable activities exhibited in reactive oxygen species scavenging may attributed to the high amount of hydrophilic phenolics present in Dillenia indica.
\end{abstract}

Key words: Dillenia indica; DPPH; Total antioxidant capacity; Reactive oxygen species

\section{INTRODUCTION}

Endogenous free radicals such as superoxide, nitric oxide and hydroxyl free radicals are produced in the human body, everyday. In recent years, oxygenderived free radicals have been reported to be closely involved in many biological symptoms such as inflammation, cancer, atherosclerosis, and coronary heart disease (Kourounakis et al., 1999; Gulcin et al., 2002). To prevent or delay the oxidation process, addition of antioxidants to foods is the most extensively used method. Although synthetic antioxidants such as butylated hydroxytoluene (BHT), butylated hydroxyanisole (BHA), and tertbutylhydroquinone (TBHQ) have been commonly

${ }^{*}$ Correspondence: Md Ashraful Alam, Department of Pharmacy, Stamford University, Bangladesh. E-mail: sonaliagun@yahoo.com used as antioxidants in foods for years, their safety has long been questioned (Branen, 1975; Ito et al., 1983). However BHT and BHA have been suspected of being responsible for liver damage and carcinogenesis (Grice, 1986; Wichi, 1988; Hettiarachchy et al., 1996). This has led to an increased interest in natural antioxidants (Braca et al., 2002; Gyamfi and Aniya, 2002; Kayano et al., 2002; Lim et al., 2002). The plant under investigation is a tree Dillenia indica belonging to the family Dilleniaceae. The fruit of Dillenia indica is said to possess tonic and laxative properties and is used of abdominal pain. The bark and leaves are astringent (Ghani, 2003). Alcoholic extract of the leaves of Dillenia indica had been reported to possess CNS depressant activities in mice (Ghani, 2003). Seeds of Dillenia indica showed antimicrobial activity (Ghani, 2003). Fruits of Dillenia indica also possessed antioxidant activity 
(Abdille et al., 2005). New pentacyclic triterpene

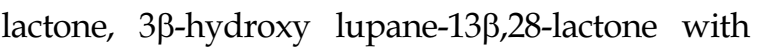
betulinaldehyde, butilin, lupeol, $\beta$-sitosterol, betulinic acid and myricetine has been isolated from the stem barks of Dillenia indica (Ghani, 2003), Two flavone, 3,4',5,7-tetrahydroxy-3'-methoxy flavone (dihydroisorhametin) and 3,5,7-trihydroxy-3'-4'dimethoxy flavone (dillenetin) has also been reported to be present in the plant (Pavanasasivam et al., 1975).

As part of investigation into natural antioxidants from local medicinal plants of Bangladesh (Alam et al., 2008a, b), in this paper, we reported a study of the antioxidant activity of the leaves of Dillenia indica. The evaluation of antioxidant power was performed in vitro by the DPPH radical scavenging, reducing power, total antioxidant capacity, total phenolics and total flavonoids assays.

\section{MATERIALS AND METHODS}

\section{Chemicals}

DPPH (1, 1-diphenyl, 2-picryl hydrazyl), TCA (Trichloro acetic acid), Ammonium molybdate, Folin-Ciocalteu, Aluminum trichloride and Ferric chloride were obtained from Sigma Chemical Co. USA. Ascorbic acid was obtained from SD Fine Chem. Ltd., Biosar, India. Sodium Nitroprusside was obtained from Ranbaxy Lab., Mohali, India. Potassium ferricyanide was obtained from May and Backer, Dagenham, UK.

\section{Plant material}

Leaves of Dillenia indica were collected from Gazipur, Bangladesh in June 2007, and identified by Professor Abdul Ghani (Stamford University, Dhaka, Bangladesh); a voucher specimen (SU-MAA2007-5) for this collection has been retained in the Pharmacognosy Laboratory, Stamford University, Dhaka, Bangladesh.

\section{Extraction}

The shade-dried leaves were coarsely powdered and extracted with mixture of methanol: water (7:3 ratios) by a Soxhlet apparatus. The solvent was completely removed by rotary evaporator and obtained greenish gummy exudates. This crude extract was used for further investigation for potential antioxidant properties.

\section{Phytochemical screening}

The freshly prepared crude extract was qualitatively tested for the presence of chemical constituents. Phytochemical screening of the extract was performed according to the procedure described earlier (Ghani, 2003).

\section{Antioxidant activity test}

The free radical scavenging capacity of the extracts was determined using DPPH (Hasan et al., 2006; Alam et al., 2008). A methanol DPPH solution $(0.004 \% \mathrm{w} / \mathrm{v})$ was mixed with serial dilutions ( 1 to $500 \mu \mathrm{g}$ ) of Dillenia indica extracts and after $10 \mathrm{~min}$, the absorbance was read at $515 \mathrm{~nm}$ using a spectrophotometer (HACH 4000 DU UV - visible spectrophotometer). Ascorbic acid was used as a standard. The inhibition curve was plotted and $\mathrm{IC}_{50}$ values obtained by probit analysis (Viturro $e t$ al., 1999).

\section{Reducing power}

The reducing power of Dillenia indica was determined according to the method previously described by Oyaizu (Oyaizu, 1986). Different concentrations of Dillenia indica extract $(100-1,000 \mu \mathrm{g})$ in $1 \mathrm{ml}$ of distilled water was mixed with phosphate buffer ( $2.5 \mathrm{ml}, 0.2 \mathrm{M}, \mathrm{pH}$ 6.6) and potassium ferricyanide $\left[\mathrm{K}_{3} \mathrm{Fe}(\mathrm{CN})_{6}\right](2.5 \mathrm{ml}, 1 \%)$. The mixture was incubated at $50^{\circ} \mathrm{C}$ for $20 \mathrm{~min}$. A portion $(2.5 \mathrm{ml})$ of trichloroacetic acid $(10 \%)$ was added to the mixture, which was then centrifuged at 3,000 rpm for $10 \mathrm{~min}$. The upper layer of the solution $(2.5 \mathrm{ml})$ was mixed with distilled water $(2.5 \mathrm{ml})$ and $\mathrm{FeCl}_{3}(0.5 \mathrm{ml}, 0.1 \%)$ and the absorbance was measured at $700 \mathrm{~nm}$. Increased absorbance of the reaction mixture indicated increased reducing power. Ascorbic acid was used as a standard. 


\section{Determination of total antioxidant capacity}

The antioxidant activity of the extracts of Dillenia indica was evaluated by the phosphomolybdenum method according to the procedure of Prieto $\mathrm{et} \mathrm{al}$. (1999). The assay is based on the reduction of Mo (VI)-Mo (V) by the extract and subsequent formation of a green phosphate/Mo $(\mathrm{V})$ complex at acid $\mathrm{pH}$. $0.3 \mathrm{ml}$ extract was combined with $3 \mathrm{ml}$ of reagent solution $(0.6 \mathrm{M}$ sulfuric acid, $28 \mathrm{mM}$ sodium phosphate and $4 \mathrm{mM}$ ammonium molybdate). The tubes containing the reaction solution were incubated at $95^{\circ} \mathrm{C}$ for $90 \mathrm{~min}$. Then the absorbance of the solution was measured at $695 \mathrm{~nm}$ using a spectrophotometer (Shimadzu, UV-150-02) against blank after cooling to room temperature. Methanol $(0.3 \mathrm{ml})$ in the place of extract is used as the blank. The antioxidant activity is expressed as the number of equivalents of ascorbic acid.

\section{Determination of total phenolic content}

The total phenolic content of extracts was determined using to the Folin-Ciocalteu method (Singelton et al., 1999). The extracts were oxidized with FolinCiocalteu reagent, and the reaction was neutralized with sodium carbonate. The absorbance of the resulting blue color was measured at $760 \mathrm{~nm}$ after $60 \mathrm{~min}$. Using galic acid as standard total phenolic content (standard curve was prepared using concentrations 2.5 - $50 \mathrm{mg} / \mathrm{l}$ ) was expressed as $\mathrm{mg}$ GA equivalent/l of extract. Data reported of two replications.

\section{Determination of total flavonoids content}

The flavonoids content was determined using a method previously described by Kumaran and Karunakaran (2007) using rutin as a reference compound. One millilitre of plant extract in methanol (50 - $250 \mu \mathrm{g} / \mathrm{ml}$ ) was mixed with $1 \mathrm{ml}$ aluminium trichloride in ethanol $(20 \mathrm{mg} / \mathrm{ml})$ and a drop of acetic acid, and then diluted with ethanol to $25 \mathrm{ml}$. The absorption at $415 \mathrm{~nm}$ was read after $40 \mathrm{~min}$. Blank samples were prepared from $1 \mathrm{ml}$ of plant extract and a drop of acetic acid, and then diluted to $25 \mathrm{ml}$ with ethanol. The absorption of standard rutin solution $(0.5 \mathrm{mg} / \mathrm{ml})$ in ethanol was measured under the same conditions. All determinations were carried out in duplicates. The amount of flavonoids in plant extracts in rutin equivalents (RE) was calculated by the following formula: $X=$ $(\mathrm{A} \times \mathrm{m} 0) /(\mathrm{A} 0 \times \mathrm{m})$, where $\mathrm{X}$ is the flavonoid content, $\mathrm{mg} / \mathrm{mg}$ plant extract in $\mathrm{RE}, \mathrm{A}$ is the absorption of plant extract solution, A0 is the absorption of standard rutin solution, $\mathrm{m}$ is the weight of plant extract in $\mathrm{mg}$ and $\mathrm{m} 0$ is the weight of rutin in the solution in $\mathrm{mg}$.

\section{RESULTS}

\section{Phytochemical screening}

Phytochemical analyses of the crude extract revealed the presence of alkaloid, tannin, gum and flavonoid (Table 1). Phytochemical analysis revealed the presence of alkaloids, gums and flavonoids copound in the methanolic extract of Dillenia indica.

\section{DPPH radical scavenging activity}

Comparison of the antioxidant activity of the extract and ascorbic acid was shown in Table 2. The

Table 2. Scavenging of free radical by crude hydroethanolic extract of Dillenia indica and ascorbic acid in DPPH method

\begin{tabular}{cc}
\hline Sample & $\begin{array}{c}\text { DPPH method } \mathrm{IC}_{50} \\
(\mu \mathrm{g} / \mathrm{ml})\end{array}$ \\
\hline $\begin{array}{c}\text { Crude Hydroethanolic } \\
\text { extract of Dillenia indica } \\
\text { Ascorbic acid }\end{array}$ & 100.53 \\
\hline
\end{tabular}

Table 1. Result of chemical group test of the methanol extract of Dillenia indica leaf

\begin{tabular}{|c|c|c|c|c|c|c|c|}
\hline Extract & Steroid & Alkaloid & Reducing sugar & Tannin & Gum & Flavonoid & Saponin \\
\hline ME of D. indica & - & + & - & ++ & + & ++ & - \\
\hline
\end{tabular}

ME: Methanol extract; (+): Present; (-): Absent 


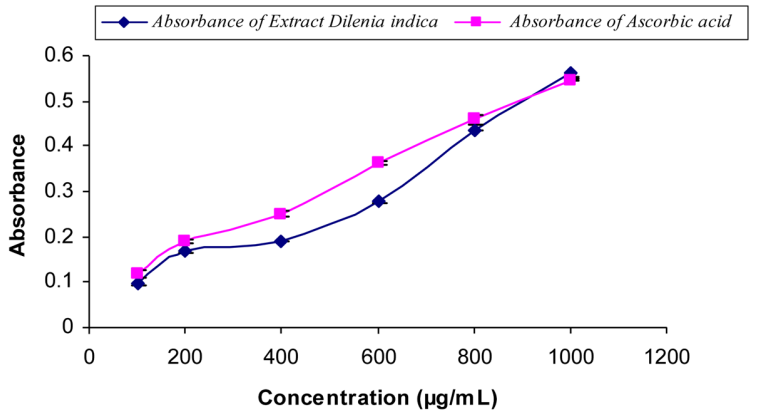

Fig. 1. Reducing power of the crude plant extract Dillenia indica and ascorbic acid. Increase in absorbance is a sign of increasing reducing power in ferric/ thiocyanate system. Values represents duplicate experiments and expressed as mean \pm standard deviation

hydro-alcoholic extract of Dillenia indica exhibited a significant dose dependent inhibition of DPPH activity, with a $50 \%$ inhibition $\left(\mathrm{IC}_{50}\right)$ at a concentration of $\mathrm{IC}_{50} 100.53 \mu \mathrm{g} / \mathrm{ml}$. The $\mathrm{IC}_{50}$ value of the extract was found to be greater than the standard, Ascorbic acid $\left(\mathrm{IC}_{50} 58.92 \mu \mathrm{g} / \mathrm{ml}\right)$.

\section{Reducing power}

Fig. 1 shows the reductive capabilities of the plant extract compared to Ascorbic acid determined using the potassium ferricyanide reduction method. The reducing power of extract of Dillenia indica was very potent and the power of the extract was increased with quantity of sample. The plant extract could reduce the most $\mathrm{Fe}^{3+}$ ions, which had a lesser reductive activity than the standard of Ascorbic acid.
Table 3. Total antioxidant capacity of extract of Dillenia indica. Values are given for two consecutive experiments and expressed as mean \pm standard deviation

\begin{tabular}{cc}
\hline $\begin{array}{c}\text { Concentration } \\
(\mu \mathrm{g} / \mathrm{mg})\end{array}$ & $\begin{array}{c}\text { Equivalent of ascorbic } \\
\text { acid }\end{array}$ \\
\hline 100 & $0.859 \pm 0.041$ \\
200 & $1.095 \pm 0.458$ \\
400 & $1.519 \pm 0.116$ \\
600 & $1.965 \pm 0.073$ \\
800 & $2.407 \pm 0.521$ \\
\hline
\end{tabular}

\section{Total antioxidant activity}

The yield of total antioxidant capacity of the methanol extract of Dillenia indica is given in Table 3. Total antioxidant capacity of Dillenia indica are expressed as the number of equivalents of ascorbic acid.

\section{Total phenolics and flavonoid content}

The total phenolics and flavonoids content of Dillenia indica extract was expressed in gallic acid and rutin equivalents respectively and are presented in Table 4. The amount of phenolic content was determined from regression equation of calibration curve $(y=0.0067 x+0.1609)$. There is positive correlation of total phenolic content as it was increased due to the increment of the concentration of extract.

Likewise phenolic content total flavonoids were also increased due to the increment of the concentration of extract. Total favonoids was obtained using the equation mentioned in the text and expressed in rutin equivalents.

Table 4. Total amount of plant phenolic compounds and flavonoids of the methanol extract of Dillenia indica

\begin{tabular}{ccc}
\hline $\begin{array}{c}\text { Concentration } \\
(\mu \mathrm{g} / \mathrm{ml})\end{array}$ & $\begin{array}{c}\text { Total Phenols mg/g plant extract } \\
(\mathrm{GAE})\end{array}$ & $\begin{array}{c}\text { Total flavonoids mg/g plant extract } \\
(\mathrm{RE})\end{array}$ \\
\hline 50 & $5.537 \pm 0.633$ & $10.433 \pm 0.442$ \\
100 & $13.000 \pm 0.633$ & $21.750 \pm 1.390$ \\
150 & $32.179 \pm 3.061$ & $30.962 \pm 2.641$ \\
200 & $32.478 \pm 5.805$ & $39.152 \pm 4.264$ \\
250 & $43.075 \pm 3.272$ & $54.651 \pm 5.683$ \\
Average & $25.25 \pm 2.681$ & $31.3896 \pm 2.884$ \\
\hline
\end{tabular}

The result of total phenol was obtained by using calibration curve but that of total favonoids was obtained using the equation mentioned in the text. 


\section{DISCUSSION}

Antioxidants which are found naturally in many foods and beverages provide health benefits in preventing diseases such as heart disease and cancer by fighting cellular damage caused by free radicals in the body (Svilaas et al., 2004). A possible mechanism mediating the protective effect is related to bioactive compounds in fruits and vegetables that reduce oxidative stress, a condition that arises when the formation of reactive oxidants (most importantly reactive oxygen species, reactive nitrogen species, and reactive iron species) outstrips the antioxidant defense, and oxidative damage occurs (Svilaas et al., 2004). Antioxidants are believed to intercept the free radical chain of oxidation and to donate hydrogen from their phenolic hydroxyl groups, thereby forming a stable end-product, which does not initiate or propagate further oxidation of lipids (Sherwin, 1978). Fruits and vegetables contain at least several hundred different types of antioxidants (i.e., electron- or hydrogendonating reductants) that may react directly with such reactive oxidants, forming products with much lower reactivity and therefore potentially protecting against oxidative damage (Halliwell, 1996; Gutteridge and Halliwell, 2000). Another mechanism involves activation of genes encoding proteins in the antioxidant defense system and/or silencing of genes that may contribute to the oxidative stress (Wild and Mulcahy, 2000). Owing to the complexity of the oxidation-antioxidation process, no single testing method is capable of providing a comprehensive view of the antioxidative profile of a sample (Parejo et al., 2002). Therefore, a multi-method approach is necessary to assess antioxidative activity. In present study, the total antioxidant effect of methanol extracts of Dillenia indica that are traditionally used in Bangladesh, were measured and compared to ascorbic acid. Three commonly accepted assays, DPPH free radical scavenging assay, reducing power and total antioxidant capacity by phosphomolibdenum method were employed to evaluate the total antioxidant effects of tested plant.

Scavenging activity for free radicals of 1.1-diphenyl2-picrylhydrazyl (DPPH) has been widely used to evaluate the antioxidant activity of natural products from plant and microbial sources. The DPPH antioxidant assay is based on the ability of 1,1diphenyl-2-picryl-hydrazyl (DPPH), a stable free radical, to decolorize in the presence of antioxidants (Alam et al., 2008). The DPPH radical contains an odd electron, which is responsible for the absorbance at $517 \mathrm{~nm}$ and also for visible deep purple colour. The essence of DPPH method is that the antioxidants react with the stable free radical i.e., $\alpha, \alpha$-diphenyl- $\beta$ picrylhydrazyl (deep violet colour) and convert it to $\alpha, \alpha$-diphenyl- $\beta$-picrylhydrazine with discolouration. The degree of discolouration indicates the scavenging potentials of the sample antioxidant. When DPPH accepts an electron donated by an antioxidant compound, the DPPH is decolorized which can be quantitatively measured from the changes in absorbance. It has been found that cysteine, glutathione, ascorbic acid, tocopherol, flavonoids, tannins, and aromatic amines (p-phenylene diamine, $\mathrm{p}$ aminophenol, etc.) reduce and decolourise DPPH by their hydrogen donating ability (Yokozawa et al., 1998). Phenolic compounds of the Dillenia indica extracts are probably involved in their antiradical activity.

The reducing ability of a compound generally depends on the presence of reductones (Duh, 1998), which have been exhibited antioxidative potential by breaking the free radical chain, donating a hydrogen atom (Gordon, 1990). The presence of reductants (i.e. antioxidants) in the fractions Dillenia indica extract causes the reduction of the $\mathrm{Fe}^{3+} /$ ferricyanide complex to the ferrous form. Therefore, the $\mathrm{Fe}^{2+}$ can be monitored by measuring the formation of Perl's Prussian blue at $700 \mathrm{~nm}$. Our data on the reducing power of the tested extracts suggest that it is likely to contribute significantly towards the observed antioxidant effect. However, the antioxidant activity of antioxidants has been attributed by various mechanisms, among which 
some of them are prevention of chain initiation, binding of transition metal ion catalysts, decomposition of peroxides, prevention of continued hydrogen abstraction, reductive capacity and radical scavenging (Diplock, 1997). Since phenolic compounds present in the extracts are a good source of electron donors, they show reducing power.

The phosphomolybdenum method was based on the reduction of Mo (VI) to Mo (V) by the antioxidant compound and the formation of a green phosphate/Mo $(\mathrm{V})$ complex with a maximal absorption at $695 \mathrm{~nm}$. The assay is successfully used to quantify vitamin $\mathrm{E}$ in seeds and, being simple and independent of other antioxidant measurements commonly employed, it was decided to extend its application to plant extracts (Prieto et al., 1999). Moreover, it is a quantitative one, since the antioxidant activity is expressed as the number of equivalents of ascorbic acid. The study reveals that the antioxidant activity of the extract is in the increasing trend with the increasing concentration of the plant extract.

Phenolic compounds, as secondary metabolite, are ubiquitous in vegetables, fruits and cereal grain. They are one kind of natural antioxidants and have multiple biological effects, in particular, play an important role in the deference against cardiovascular disease, aging and cancer. In our present study, antioxidant activity of Dillenia indica extracts assayed through the three methods DPPH radical scavenging, reducing power and total antioxidant capacity was found to follow the increasing order with increasing of concentration. This is similar to the extent of antioxidant activity of the extract is in accordance with the amount of phenolics present in that extract. In the present study it is found that the methanol extract of Dillenia indica contains substantial amount of phenolics anf flavonoids and it is the extent of phenolics present in this extract is responsible for its marked antioxidant activity as assayed through various in vitro models. Several reports have conclusively shown close relationship between total phenolic content and antioxidative activity of the fruits and vegetables (Vinson et al.,
1998; Deighton et al., 2000). It has been reported that phenolic compounds with ortho- and paradihydroxylation or a hydroxy and a methoxy group are more effective than simple phenolics (Frankel et al., 1995). Since the chemical composition and structures of active components are important factors governing the efficacy of natural antioxidants the extract of Dillenia indica needs their characterization.

\section{CONCLUSION}

The extract found to have different levels of antioxidant activity in all the systems tested. In view of the discussion, it can be concluded that the methanolic extract possesses the antioxidant substances which may be a potential mechanism using this plants extract in folkloric remedies. Further studies are warranted for the isolation and identification of individual phenolic compounds and also in vivo studies are needed for understanding their mechanism of action as an antioxidant.

\section{REFERENCES}

Abdille MH, Singh RP, Jayaprakasha GK, Jena BS. (2005) Antioxidant activity of the extracts from Dillenia indica fruits. Food Chem. 90, 891-896.

Alam MA, Ghani A, Subhan N, Rahman MM, Haque MS, Majumder MM, Mazumder MEH, Akter RA, Nahar L, Sarker SD. (2008) Antioxidant and membrane stabilizing properties of the flowering tops of Anthocephalus cadamba. Nat. Prod. Commun. 3, 65-67. Alam MA, Nyeem MAB, Awal MA, Mostofa M, Alam MS, Subhan N, Rahman MM. (2008) Antioxidant and hepatoprotective action of the crude methanolic extract of the flowering top of Rosa damascena. Orient. Pharm. Exp. Med. 8, 164-170.

Braca A, Sortino C, Politi M, Morelli I, Mendez J. (2002) Antioxidant activity of flavonoids from Licania licaniaeflora. J. Ethnopharmacol. 79, 379-381.

Branen AL. (1975) Toxicology and biochemistry of butylated hydroxyanisole and butylated hydroxytoluene, J. Am. Oil Chem. Soc. 52, 59-63.

Deighton N, Brennan R, Finn C, Davies HV. (2000) Antioxidant properties of domesticated and wild 
Rubus species. J. Sci. Food Agric. 80, 1307-1313.

Diplock AT. (1997) Will the good fairies please prove us that vitamin E lessens human degenerative disease? Free Radic. Res. 27, 511-532.

Duh PD, Tu YY, Yen GC. (1999) Antioxidant activity of water extract of Harng Jyur (Chrysanthemum moifolium Ramat). Lebensm-Wiss Technol 32, 269-277.

Frankel EN, Waterhouse AL, Teissedre PL. (1995) Principal phenolic phytochemicals in selected California wines and their antioxidant activity inhibiting oxidation of human low-density lipoprotein. J. Agric. Food Chem. 43, 890-894.

Ghani A. (2003) Medicinal plants of Bangladesh with chemical constituents and uses. 2nd ed. Asiatic society of Bangladesh, p. 208-209.

Gordon MH. (1990). The mechanism of the antioxidant action in vitro. In: Hudson BJF (ed.), Food Antioxidants. London: Elsevier, p. 1-18.

Grice HC. (1986). Safety evaluation of butylated hydroxytoluene (BHT) in the liver, lung and gastrointestinal tract. Food Chem. Toxicol. 24, 1127-1130.

Gulcin I, Buyukokuroglu ME, Oktay M, Kufrevioglu OI. (2002) On the in vitro antioxidant properties of melatonin. J. Pineal Res. 33, 167-171.

Gutteridge JM, Halliwell B. (2000) Free radicals and antioxidants in the year 2000: a historical look to the future. Ann. N.Y. Acad. Sci. 899, 136-147.

Gyamfi MA, Aniya Y. (2002) Antioxidant properties of Thonningianin A, isolated from the African medicinal herb, Thonningia sanguine. Biochem. Pharmacol. 63, 1725-1737.

Halliwell B. (1996) Antioxidants in human health and disease. Annu. Rev. Nutr. 16, 33-50.

Hasan MS, Ahmed MI, Mondal S, Uddin SJ, Masud MM, Sadhu SK, Ishibashi M. (2006) Antioxidant, antinociceptive activity and general toxicity study of Dendrophthoe falcata and isolation of quercitrin as the major component. Orient. Pharm. Exp. Med. 6, 355-360.

Hettiarachchy NS, Glenn KC, Gnanasambandam R, Johnson MG. (1996) Natural antioxidant extract from fenugreek (Trigonella foenumgraecum) for ground beef patties. J. Food Sci. 61, 516-519.

Ito N, Fukushima S, Hasegawa A, Shibata M, Ogiso T. (1983) Carcinogenicity of butylated anisole in F344 rats, J. Natl. Cancer Inst. 70, 343-347.

Kumaran A, Karunakaran AJ. (2007) In vitro antioxidant activities of methanol extracts of five Phyllanthus species from India. LWT 40, 344-352.

Kayano S, Kikuzaki H, Fukutsuka N, Mitani T, Nakatani N. (2002) Antioxidant activity of prune (Prunus domestica L.) constituents and a new synergist, J. Agric. Food Chem. 50, 3708-3712.

Kourounakis AP, Galanakis D, Tsiakitzis K. (1999) Synthesis and pharmacological evaluation of novel derivatives of anti-inflammatory drugs with increased antioxidant and anti-inflammatory activities. Drug Dev. Res. 47, 9-16.

Lim SN, Cheung PCK, Ooi VEC, Ang PO. (2002) Evaluation of antioxidative activity of extracts from a brown seaweed, Sargassum siliquastrum, J. Agric. Food Chem. 50, 3862-3866.

Oyaizu M. (1986) Studies on product of browning reaction prepared from glucose amine. Jpn. J. Nutr. 44, 307-315.

Parejo I, Viladomat F, Bastida J, Rosas-Romero A, Flerlage N, Burillo J, Codina C. (2002). Comparison between the radical scavenging activity and antioxidant activity of six distilled and nondistilled Mediterranean herbs and aromatic plants. J. Agric. Food Chem. 50, 6882-6890.

Pavanasasivam G, Sultanbawa MUS. (1975) Chemical investigation of ceylonese plants, Part XII. (+)3,4',5,7-Tetrahydroxy-3' -methoxyflavanone $[(+)-$ dihydroisorhamnetin] and 3,5,7-trihydroxy-3',4'dimethoxyflavone (dillenetin): two new natural products from Dillenia indica L. J. Chem. Soc. Perkin Trans. 1, 612-613.

Prieto P, Pineda M, Aguilar M. (1999) Spectrophotometric quantitation of antioxidant capacity through the formation of a phosphomolybdenum complex: Specific application to the determination of vitamin E. Anal. Biochem. 269, 337-341.

Sherwin ER. (1978) Oxidation and antioxidants in fat and oil processing. J. Am. Oil. Chem. Soc. 55, 809-814.

Singelton VR, Orthifer R, Lamuela-Raventos RM. (1999) Analysis of total phenols and other oxidation substrates and antioxidants by means of FolinCiocalteu reagent. Methods in Enzymol. 299, 152-178.

Svilaas A, Sakhi AK, Andersen LF, Svilaas T, Strom EC, Jacobs DR Jr, Ose L, Blomhoff R. (2004) Intakes of antioxidants in coffee, wine and vegetables are correlated with plasma carotenoids in humans. J. Nutr. 134, 562-567. 
Vinson JA, Hao Y, Zubic SK (1998) Food antioxidant quantity and quality in foods: Vegetables. J. Agric. Food Chem. 46, 3630-3634.

Viturro C, Molina A, Schmeda-Hischmann G. (1999) Free radical scavengers from Mutisia friesiana (Asteraceae) and Sanicula graveolens (Apiaceae). Phytother. Res. 13, 422-424.

Wichi HP. (1988) Enhanced tumor development by butylated hydroxyanisole (BHA) from the prospective of effect on forestomach and oesophageal aquamous epithelium. Food Chem. Toxicol. 26, 717-723.

Wild AC, Mulcahy RT. (2000) Regulation of gammaglutamylcysteine synthetase subunit gene expression: insights into transcriptional control of antioxidant defenses. Free Radic. Res. 32, 281-301.

Yokozawa T, Chen CP , Dong E, Tanaka T, Nonaka GI, Nishioka I. (1998) Study on the inhibitory effect of tannins and flavonoids against the 1,1-Diphenyl2-picrylhydrazyl radical. Biochem. Pharmacol. 56, 213-222. 